\title{
Prediction of Height, Breast Height Diameter and Volume of Eucalyptus microcorys of Sri Lanka
}

\author{
P.G.A.L. Kumara, S.M.C.U.P. Subasinghe* \\ Department of Forestry and Environmental Science, University of Sri Jayewardenepura, Sri Lanka \\ *upuls@sjp.ac.lk
}

\begin{abstract}
Eucalyptus microcorys is the most valuable Eucalyptus species growing in Sri Lanka. Although the extant of government owned E. microcorys plantations is comparatively small, the attention of private sector planters has been drawn by this species. Therefore the present study was conducted with the objective of predicting the variation of tree height, breast height diameter (dbh) and total stem volume with the tree age.
\end{abstract}

Fourteen E. microcorys plantations were selected for this study from Halgranoya and Nuwara Eliya Forest Ranges of Nuwara Eliya Forest Division. Those plantations were three to 24 years old and the extents varied from 4.5 to 32.5 ha. Circular sample plots of 0.02 ha drawn at random were used for data collection. The number of sample plots varied with the extents of the selected plantations.

Total height and dbh of each tree were measured using standard methods. Then each tree stem was visually divided into a few sections and the length, bottom diameter, mid diameter and top diameter of each section were measured. Using these measurements, volume of each section was estimated by Newton's formula and the total stem volume was calculated by adding all section volumes. The shape of the final section was assumed to be a cone.

When tested, the selected plantations did not indicate significant site quality differences. The tree height and dbh prediction models were constructed assuming them as functions of the age. Tree volume model was built as a function of tree height and dbh. All possible transformations of the candidate variables were tested in constructing those models and the best models were selected based on $\mathrm{R}^{2}$ values and distribution of standard residuals. The selected best three models for height-age, diameter-age and volume-dbh and height relationships had $\mathrm{R}^{2}$ values of $80.1 \%, 79.5 \%$ and $98.2 \%$ respectively. Further, the standard residual distributions of the selected models did not indicate significant biases.

Using those models, a two-parameter volume prediction model for E. microcorys was also constructed.

Keywords: Eucalyptus microcorys, Stem volume prediction, Two-parameter volume table 